\title{
Welfare Costs of Inflation in a Menu Cost Model
}

\author{
Ariel Burstein and Christian Hellwig*
}

\section{January 2008}

Recent years have seen substantial progress in our understanding of pricing decisions at the micro level. Access to large scale data sources on prices at the level of individual products has given us rich information on how frequently prices change, by what magnitudes, and how the aggregation of price changes in individual firms maps into aggregate inflation (see, among many others, Mark Bils and Peter J. Klenow 2005). These facts about price movements are a key input in recent quantitative models of the aggregate effects of nominal rigidities (e.g. Mikhail Golosov and Robert E. Lucas 2007).

In this paper, we use both the new facts and the new quantitative models to revisit an old question, namely, that of quantifying the welfare benefits of low inflation. Our model includes two channels through which steady-state inflation affects welfare. The first channel is based on the presence of nominal rigidities, which induce fluctuations in relative prices between products whose prices adjust, and products whose prices remain fixed, thus distorting the composition of output away from efficiency, and lowering aggregate productivity and welfare. These relative price distortions are eliminated when inflation is zero, so that the need for price adjustment is eliminated. This argument is at the core of a large literature on optimal monetary policy (see, for example, Michael Woodford 2003). The second channel, dating back to Milton Friedman (1969) and more recently Lucas (2000), stems from the effects of inflation on the opportunity cost of holding real money balances. ${ }^{1}$

\footnotetext{
*Burstein and Hellwig: Department of Economics, UCLA, Los Angeles CA 90095

${ }^{1}$ Other references include Jordi Gali (2007) and Stephanie Schmitt-Grohe, and Martin Uribe (2005) for
} 
We quantitatively evaluate these two channels in a menu cost model of price adjustment which is calibrated to capture key observations of price adjustment at the micro level. We base our model and calibration of product-level price changes on our earlier work in Burstein and Hellwig (2007) extended with a complete specification of a representative household's preferences.

Our main finding is that the contribution of relative price distortions to the welfare effects of inflation in our calibrated menu cost model is minimal - an order of magnitude smaller than the effects resulting from the opportunity cost of real money balances. Moreover, commonly used sticky price models that are based on exogenously staggered price adjustment (such as Calvo pricing models) ${ }^{2}$ and abstract from product-level variation in costs and demand substantially overstate the effects of relative price distortions relative to our menu cost model, in which price adjustment is endogenous, and idiosyncratic shocks generate the need for price adjustment even at low rates of inflation.

\section{Model}

We consider a standard general equilibrium menu cost model with decreasing returns to scale in production, and idiosyncratic shocks to both cost and demand in order to match observed fluctuations in prices and market shares at the level of individual varieties. We focus on steady-state equilibria with constant money growth.

A. Household Preferences: The representative household's preferences over a final consumption good $C_{t}$, labor supply $N_{t}$, and real balances $M_{t} / P_{t}$ are given by

$$
\begin{gathered}
U=\sum_{t=0}^{\infty} \beta^{t} u\left(C_{t}, \frac{M_{t}}{P_{t}}, N_{t}\right), \text { where } \\
u\left(C, \frac{M}{P}, N\right)=\log \left(\left[b C^{(\eta-1) / \eta}+(1-b)\left(\frac{M}{P}\right)^{(\eta-1) / \eta}\right]^{\eta /(\eta-1)}\right)+\psi \log (1-N)
\end{gathered}
$$

the welfare costs of sticky prices, and Ricardo Lagos and Randall Wright (2005), and Carlos E. da Costa and Iván Werning (2007) for the welfare costs of changes in real money balances.

${ }^{2}$ Michael Kiley (2000) and Andrew Levin, Alexei Onatski, John Williams, and Noah Williams (2005) compare the welfare costs of inflation in Calvo and Taylor exogenous staggered pricing models. 
with $\beta<1$. The household chooses $\left\{C_{t}, N_{t}, B_{t}, M_{t}\right\}_{t=0}^{\infty}$ to maximize (1), subject to

$$
M_{t+1}+B_{t+1}=M_{t}+\left(1+i_{t}\right) B_{t}+W_{t} N_{t}-P_{t} C_{t}+T_{t}+\Pi_{t}
$$

where $M_{t}$ denotes the household's demand for nominal balances, $B_{t}$ nominal bonds (which are in zero net supply), $P_{t}$ the price of the consumption good, $W_{t}$ the nominal wage rate, $\Pi_{t}$ the aggregate profits of the corporate sector, and $T_{t}$ a lump sum monetary transfer the household receives at the beginning of each period. The growth rate of money is constant at $\mu=M_{t} / M_{t-1}-1$, so $T_{t}=\mu M_{t}$.

In a steady-state equilibrium with constant money growth, the nominal interest rate is constant and equal to $1+i_{t}=(1+\mu) / \beta$, and the normalized levels of wages and final goods prices $\hat{W}=W / M$ and $\hat{P}=P / M$, aggregate consumption $C$, labor supply $N$, and real balances $\hat{P}^{-1}$ are all constant over time, and satisfy the household's first-order conditions for money demand and labor supply.

B. Production Technologies and Pricing Decisions: There is a perfectly competitive industry producing the final consumption good from a measure 1 continuum of varieties, according to the CES technology $C_{t}^{(\theta-1) / \theta}=\int_{0}^{1} a_{i t}^{1 / \theta} c_{i t}^{(\theta-1) / \theta} d i$, where $a_{i t}$ denotes an idiosyncratic demand shock for variety $i$ in period $t$. Standard arguments imply a demand for variety $i$ by the final good sector given by $c_{i t}=a_{i t}\left(p_{i t} / P_{t}\right)^{-\theta} C_{t}$, and an equilibrium price for the final consumption good $P_{t}$ given by $P_{t}^{1-\theta}=\int_{0}^{1} a_{i t} p_{i t}^{1-\theta} d i$, where $p_{i t}$ denotes the price of variety $i$ in period $t$.

Each variety is produced by a single monopolistic firm, using labor $n_{i t}$ according to the technology $c_{i t}=z_{i t} n_{i t}^{\alpha}$, where $z_{i t}$ is an idiosyncratic cost shock for variety $i$ in period $t$ that shapes its productivity. The parameter $\alpha \leq 1$ reflects the presence of decreasing returns to scale or firm-specific inputs that lead to upwards-sloping marginal costs. Firms' nominal profits in period $t$, exclusive of menu costs, are given by $\pi_{i t}=p_{i t} c_{i t}-W_{t}\left(\frac{c_{i t}}{z_{i t}}\right)^{1 / \alpha}$. Idiosyncratic cost and demand shocks follow each follow an AR1 process: $\ln a_{i t}=\rho_{a} \ln a_{i t-1}+$ 
$\varepsilon_{i t}^{a}$, and $\ln z_{i t}=\rho_{z} \ln z_{i t-1}+\varepsilon_{i t}^{z}$, where $\varepsilon_{i t}^{a} \sim \mathcal{N}\left(0, \sigma_{a}^{2}\right)$ and $\varepsilon_{i t}^{z} \sim \mathcal{N}\left(0, \sigma_{z}^{2}\right)$ are iid across varieties and over time. We let $\Psi\left(s^{\prime} \mid s\right)$ denote the transition probability function associated with the idiosyncratic shocks, where $s=(a, z)$.

In each period, firms observe their draw of demand and cost shocks $s_{i t}=\left(a_{i t}, z_{i t}\right)$, and then decide whether to hire $F$ units of labor to change their price or otherwise keep it constant. Let $V(\hat{p} ; s)$ denote the present value of profits for a firm with current normalized price $\hat{p}=p / M$ (prior to its price adjustment decision) and idiosyncratic state $s$. This value function is characterized by the following Bellman equation:

$$
V(\hat{p} ; s)=\max \left\{V\left(p^{*}(s) ; s\right)-\hat{W} F, \hat{\pi}(\hat{p} ; s)+\beta \int_{s^{\prime}} V\left(\hat{p} /(1+\mu) ; s^{\prime}\right) d \Psi\left(s^{\prime} \mid s\right)\right\},
$$

where $p^{*}(s)=\arg \max _{\hat{p}} V(\hat{p} ; s)$ is the firm's optimal normalized price, and $\hat{\pi}(\hat{p} ; s)=$ $\pi_{i t} / M$ denotes the firm's normalized per-period profits. The firm's optimal decision rule $\tilde{p}(\hat{p} ; s)$ is characterized by two values $\underline{p}(s), \bar{p}(s)$ around the optimal price $p^{*}(s)$, for which $V(\underline{p}(s) ; s)=V(\bar{p}(s) ; s)=V^{*}(s)-\hat{W} F$. The firm keeps its price constant if $\hat{p} \in$ $[\underline{p}(s) ; \bar{p}(s)]$, and adjusts its price to $p^{*}(s)$ otherwise.

The firms' optimal decision rule $\tilde{p}(\hat{p} ; s)$ in turn generates an ergodic cross-sectional distribution $\Phi$ over price-state pairs $(\hat{p} ; s)$. From $\Phi$, we compute the normalized price level and the aggregate demand for labor $N$, where the latter consists of both the labor employed in production $N^{P}$, and the labor employed in changing prices $N^{F}$. A steady-state equilibrium is therefore characterized by an optimal pricing rule $\tilde{p}$, a cross-sectional distribution $\Phi$, and $\{C, N, \hat{P}, \hat{W}\}$, so that $\tilde{p}$ solves the Bellman equation (3), $\Phi$ is stationary given the law of motion induced by $\tilde{p}$, and $\{C, N, \hat{P}, \hat{W}\}$ satisfy the household optimality conditions, the price indexing rule and the labor supply rule.

\section{Calibration}

Our model consists of the preference parameters $(\psi, b, \eta, \beta)$, the demand elasticity $\theta$, the returns to scale $\alpha$, the menu cost $F$, the parameters $\left(\rho_{a}, \rho_{z} ; \sigma_{a}, \sigma_{z}\right)$ that govern the processes 
of the idiosyncratic cost and demand shocks, and the steady-state inflation rate $\mu$. Each time period corresponds to one month. As our benchmark, we set $\mu=0.0017$ to match a steady-state annual inflation rate of $2.2 \%$. We set $\beta=0.995$ to match an annual real interest rate of $6 \%$.

On the household side, we set $\psi$ so that $N=1 / 3$ in steady-state in our benchmark economy. We set $b=0.74$ and $\eta=0.39$ to be consistent with the estimated money demand function in V.V. Chari, Patrick Kehoe and Ellen McGrattan (2002); following Lucas (2000), these parameters determine the opportunity costs of real balances as the area under the estimated money demand curve. ${ }^{3}$ We refer to this benchmark as the 'MUF' (money-in-theutility-function) economy. For comparison purposes, we also consider a 'constant velocity' version of our model, in which velocity $(C \hat{P})^{-1}$ is held constant and real balances are eliminated from the utility function.

We choose the firm-side parameters using the data sources and the procedure that was described in Burstein and Hellwig (2007). After setting $\rho_{a}=\rho_{z}=0.5$, the firms' pricing problem depends on $F, \theta, \alpha, \sigma_{a}$, and $\sigma_{z}$. We calibrate these five parameters to match moments on log-prices and log-market shares that we obtain using a scanner data from a large chain of supermarkets in the Chicago area (Dominick's). ${ }^{4}$ We target the following four benchmark moments: $(i)$ the frequency of price adjustment (excluding temporary markdowns, prices change on average every 4.5 months), $(i i)$ the average magnitude of price changes, which is 10\%, (iii) the variability of month-to-month changes in market shares, which is roughly $25 \%$, both when prices change, and when they don't, and (iv) the correlation of changes in prices and shares, conditional on the price changing, which is roughly -0.2 in our data.

We complement these 4 moments with the following additional observations: $(v)$ based

\footnotetext{
${ }^{3}$ More specifically, their estimation of $b=0.94$ was based on quarterly data, while a period in our model corresponds to one month. We also considered different parameter values for $b$ and $\eta$, and alternative utility functions that depart from the logarithmic preferences, with little effect on our main conclusions.

${ }^{4}$ We focus on market shares, as opposed to physical quantities, to isolate fluctuations at the individual variety level from fluctuations at the sectoral level, which our model abstracts from.
} 
on empirical studies, firms do not spend, on average, much more than $1 \%$ of revenues in changing prices, $(v i)$ almost $60 \%$ of all price changes are increases, but they are about $15 \%$ smaller than decreases, and (vii) price changes are 5\% more likely when the original price is below average. They are about $20 \%$ more likely when the original market share is above average.

In Burstein and Hellwig (2007), we describe in detail how these additional moments enable us to determine the choice of parameters. For our benchmark calibration, targeting these moments leads to parameter values of $\theta=4.4, \alpha=0.55, \sigma_{a}=25.7 \%, \sigma_{z}=9.7 \%$ and $F=0.0453$, which match these eight observations almost exactly, independently of the values of $b$ and $\eta$. We consider two alternative parameterizations, one with near constant returns $(\alpha=0.99)$, selecting the other four parameters to match observations (i)-(iv) (but missing out on the other four), and another with $\theta=8$ and $\alpha=0.65$, which is in the range of values used in calibrations of aggregate sticky price models with exogenous staggering. In the latter we choose the other three parameters to target observations (i)-(iii). This requires setting $\sigma_{a}=0$, which still leaves us with a variability of market shares that is slightly higher than our target.

\section{Results}

We consider the welfare effects of increasing inflation from a steady-state annual inflation rate of $2.2 \%$ by $10 \%$. We report welfare changes in terms of consumption-equivalent variation. We first compute the steady-state equilibrium in the calibrated economy, using the parameters reported in the previous section. Next, we compute the new steady state that results from a change in the steady-state inflation rate $\mu$. Our welfare measure is computed as the percentage increase or reduction in steady-state consumption in the first economy that would make the household just indifferent between the equilibrium allocations in the first and the second economy.

Table 1 presents the welfare losses or gains under different parameterizations of the model, for a $10 \%$ increase in inflation. Each column displays the results for different values of $\alpha$ and 
$\theta$ (our benchmark calibration is in column 1). Each row displays the results for the MUF and constant velocity economies, with flexible prices, menu costs, and Calvo pricing (where the adjustment parameter is set equal to the measured frequency of price adjustment). In the omitted economy with constant velocity and flexible prices, the welfare costs of inflation are zero by construction.

\begin{tabular}{||c||c||c||c||}
\hline \hline \multicolumn{4}{||c||}{ Table 1: Welfare Costs of 10\% Increase in Inflation (in percent) } \\
\hline \hline \multicolumn{4}{|c||}{ (negative numbers indicate losses) } \\
\hline \hline MUF with menu costs & $\alpha=0.55, \theta=4.4$ & $\alpha=0.65, \theta=8$ & $\alpha=0.99, \theta=1.55$ \\
\hline \hline Constant velocity with menu costs & -1.31 & -1.40 & -1.97 \\
\hline MUF with flexible prices & 0.01 & -0.12 & 0.01 \\
\hline \hline MUF with Calvo pricing & -1.33 & -1.28 & -1.97 \\
\hline Constant velocity with Calvo pricing & -2.09 & -6.70 & -2.06 \\
\hline \hline
\end{tabular}

Three results emerge from Table 1 . The first one summarizes the main finding of our paper.

Result 1: The effect of menu costs on the welfare costs of inflation is negligible, relative to the opportunity cost of real money balances.

This result follows from comparing the first row of Table 1 with the third, or from comparing the second row with the zero welfare costs of a constant velocity flexible price economy. Our exercises suggest that the opportunity costs of real balances lead to welfare costs of roughly $1.3 \%$ to $2 \%$ of consumption. In comparison, adding menu costs to either the MUF or the constant velocity economy changes the welfare costs of inflation by less than $0.1 \%$ in all cases, and some cases, it may actually increase welfare.

Our second result shows that the exact form of nominal rigidities has a large impact on the welfare costs of inflation. 
Result 2: The welfare costs of inflation are much higher in an economy with Calvo-style price staggering, than in a menu cost economy.

Comparing the first and second with the fourth and fifth rows in Table 1, Calvo-style staggered pricing raises the welfare costs of inflation by anywhere from $0.1 \%$ to $5 \%$ relative to the menu cost model. These differences can be larger than the welfare costs of inflation stemming from the opportunity costs of real money balances displayed in Row 3 .

Our third result highlights the role of the parameter choice for our quantitative results.

Result 3: The returns to scale and demand elasticity parameters are important in determining the welfare costs of inflation.

This follows from the substantial variation in our welfare measures across the three columns in Table 1; the one exception to this finding is the constant velocity menu cost economy, in which the welfare costs of inflation are negligible for any choice of parameters. These parameters help determine the degree of pricing complementarities and the business cycle implications of nominal shocks; the same parameters also turn out to affect the welfare costs of inflation.

These two parameters influence the contribution of price rigidities to the welfare costs of inflation since they determine to what extent relative price distortions translate into inefficient variation in quantities and marginal costs across firms. If a firm charges a price that is too low, it will sell more, at a higher cost, the higher is $\theta$ and the lower is $\alpha$. In column 3, with near constant returns and low elasticity of demand, these effects are very small. In column 2, with a low $\alpha$ and high $\theta$, Calvo pricing has a large welfare cost (even larger than those stemming from the opportunity costs of real balances).

Somewhat more surprisingly, these parameters also affect the welfare costs of inflation in the MUF economy with flexible prices. This happens because the returns to scale and demand elasticity interact with the opportunity costs of real balances through the determination of wages, with the former entering the firms' optimal pricing and labor demand, and the latter affecting the households' labor supply. 
Result 3 highlights the importance of guiding the calibration of parameters by micro data. First, an accurate assessment of the effects of nominal rigidities for relative price distortions and welfare ought to be based on a calibration that explicitly attempts to target product-level movements in relative prices, as we do in our benchmark calibration in column 1. Second, through the general equilibrium interaction, the firms' pricing behavior affects the household's decisions, including its willingness to hold real balances. Therefore, an accurate evaluation of the opportunity cost channel still requires a careful calibration of the firms' pricing behavior and labor demand, even when the relative price distortions only contribute minimally to the overall welfare costs of inflation.

\section{Discussion}

We take away two important findings from the above calibration exercise. First, menu costs have only a negligible impact on the welfare effects of inflation - this is yet another instance in which a menu cost economy looks more similar to a flexible price economy than one with exogenous staggering. Second, the exact form of nominal rigidities and the choice of parameters matter for the welfare results; a model with exogenous Calvo staggered pricing leads to very different welfare conclusions than a menu cost model where price adjustment is endogenous. We conclude our paper by briefly discussing what is behind these two results.

Our calibrated menu cost model differs from the standard Calvo model in several respects.

First, by choosing the timing of adjustment, as well as the prices that are set, firms have a second adjustment margin that serves to absorb marginal cost fluctuations. This added

flexibility is one reason why changes in inflation have smaller effects in a menu cost than in a time-dependent pricing model. By choosing when to adjust their prices, firms can limit relative price distortions.

Second, in sticky price models firms have a motive to respond to inflation by charging higher prices than optimal given the current conditions, to insure against the erosion of future profits due to inflation. This motive is much more sensitive to inflation in a model 
where the option to reprice is outside the firm's control, than in a menu cost model, where the option to reprice is under the firm's control.

Third, the presence of idiosyncratic cost and demand shocks leads to additional reasons for price changes, and relative price distortions, even when inflation is low. The observed large movements in prices and market shares of individual varieties at a monthly frequency suggests that this is an important consideration in the firms' pricing decisions, and that inflation may only play a secondary role. Even a $12 \%$ rate of inflation per annum seems small compared to the product-specific marginal cost and demand fluctuations that are needed to generate price changes of $10 \%$ on average every 4.5 months.

Fourth, menu costs provide an additional consideration for efficiency that is not present in the Calvo model, namely that inflation may alter the frequency of price adjustment and hence the resources that are absorbed by the menu cost.

\begin{tabular}{||c|c|c|c|c||}
\hline \hline \multicolumn{2}{||c||}{ Table 2: Implications of Inflation Increase on Prices } \\
\hline \hline & \multicolumn{2}{|c||}{ Menu Costs } & \multicolumn{2}{|c||}{ Calvo } \\
\cline { 2 - 6 } & low $\mu$ & high $\mu$ & low $\mu$ & high $\mu$ \\
\hline \hline Average duration of prices (months) & 4.64 & 4.46 & 4.50 & 4.50 \\
\hline Average magnitude of price change & $10.3 \%$ & $10.3 \%$ & $2.3 \%$ & $4.5 \%$ \\
\hline Fraction of price increases & 0.58 & 0.73 & 0.61 & 0.90 \\
\hline Average magnitude of price increases & 0.86 & 0.89 & 1.32 & 4.29 \\
\hline \hline Average magnitude of price decreases & $5.6 \%$ & $5.6 \%$ & $2.3 \%$ & $4.1 \%$ \\
\hline Dispersion of log prices & 1.00 & 1.00 & 0.97 & 0.95 \\
\hline \hline
\end{tabular}

Table 2 summarizes, for our benchmark parameterization $(\alpha=0.55, \theta=4.4)$, how measures of price movements, price dispersion and aggregate productivity $C /\left(N^{P}\right)^{\alpha}$ respond to the change in inflation in both the Calvo and the Menu Cost model, and thereby helps us shed light on how these model features impact the results. ${ }^{5}$

\footnotetext{
${ }^{5}$ Our measure of aggregate productivity takes into account the presence of labor (with a share $\alpha$ ) and a
} 
As can be seen from this table, the change in inflation has very different effects in a menu cost model than in a Calvo model. In the Calvo model, higher inflation leads to bigger increases and smaller decreases in prices, a higher fraction of increases relative to decreases, and an increase in the average magnitude of price changes and in price dispersion. This in turn translates into a substantial decline in aggregate productivity and welfare - exactly in line with the theoretical argument.

In contrast, in the menu cost model, inflation has virtually no effect on price dispersion and on the average magnitude of price changes, suggesting that the extent to which firms are willing to absorb marginal cost fluctuations without adjusting prices doesn't change much with inflation. With very small changes in the size of relative price distortions, aggregate productivity remains roughly unchanged, and with the overall duration of prices remaining roughly constant, the resources absorbed by the menu cost also don't change much. Together, this explains the fact that welfare effects are minimal. Instead, inflation is almost entirely absorbed by the extensive margin of price adjustment, as there is a substantial increase in the fraction of price changes that are increases and a reduction in the number of price cuts. ${ }^{6}$

fixed firm-specific factor normalized to one.

${ }^{6}$ Gagnon (2007) reports that this is consistent with evidence of price adjustment in higher inflation environments, where changes in the inflation rate mainly lead to a larger fraction of price adjustments that are increases, with little effect on the magnitudes. 


\section{REFERENCES}

Bils, Mark, and Peter J. Klenow (2004), "Some Evidence on the Importance of Sticky Prices," Journal of Political Economy, 112, 947-985.

Burstein, Ariel, and Christian Hellwig (2007), "Prices and Market Shares in a Menu Cost Model," NBER Working paper 13455.

Chari, V V, Patrick Kehoe, and Ellen McGrattan (2002), "Can Sticky Price Models Generate Volatile and Persistent Real Exchange Rates?," Review of Economic Studies, vol. 69(3), 533-63.

da Costa, Carlos E., and Iván Werning (2007), "On the Optimality of the Friedman Rule with Heterogeneous Agents and Non-Linear Income Taxation," forthcoming Journal of Political Economy.

Friedman, Milton (1969), "The Optimum Quantity of Money and Other Essays," London: Macmillan.

Gagnon, Etienne (2007), "Price Setting during Low and High Inflation: Evidence from Mexico," mimeo, Federal Reserve Board

Gali, Jordi (2007), "Monetary Policy, Inflation and the Business Cycle" monograph, CREI.

Golosov, Mikhail, and Robert Lucas (2007), "Menus Menu Costs and Phillips Curves," Journal of Political Economy, 115, 171-199

Kiley, Michael (2000), "Endogenous Price Stickiness and Business Cycle Persistence," Journal of Money, Credit and Banking, vol. 32(1), 28-53.

Lagos, Ricardo, and Randall Wright (2005), "A Unified Framework for Monetary Theory and Policy Analysis," Journal of Political Economy, vol. 113(3), 463-484. 
Levin, Andrew, Alexei Onatski, John Williams, and Noah Williams (2005), "Monetary Policy Under Uncertainty in Micro-Founded Macroeconometric Models," NBER Working Paper 11523.

Lucas, Robert (2000), "Inflation and Welfare," Econometrica, 68, 247-74.

Schmitt-Grohe, Stephanie, and Martin Uribe (2005), "Optimal Fiscal and Monetary Policy in a Medium-Scale Macroeconomic Model," in Gertler, Mark and Kenneth Rogoff, eds., NBER Macroeconomics Annual 2005, MIT Press: Cambridge MA, 2006, 383-425.

Woodford, Michael (2003), Interest and Prices: Foundations of a Theory of Monetary Policy, Princeton, NJ: Princeton University Press. 